\title{
Parametrical study of the cementitious materials degradation under external sulfate attack through numerical modeling
}

\author{
Anthony Soive ${ }^{\mathrm{a}, \mathrm{b}}$, Emmanuel Roziere ${ }^{\mathrm{b}}$, Ahmed Loukili ${ }^{\mathrm{b}, *}$ \\ ${ }^{a}$ Centre d'Etudes et d'Expertises sur les Risques, l'Environnement, la Mobilité et l'Aménagement (Cerema), Nantes, France \\ ${ }^{\mathrm{b}}$ LUNAM Université, Institut de Recherche en Génie Civil et Mécanique (GeM), UMR-CNRS 6183, Ecole Centrale de Nantes, 1 rue de la Noë, 44321 Nantes, France
}

\begin{abstract}
Underground concrete structures may be subjected to external sulfate attack and their long-term performance is of concern. A coupled transport/chemical numerical model has been compared to experimental data obtained on a cement paste exposed to external sulfate attack thanks to recent developments in experimental analysis such as scanning electron microscopy and image analysis that provided total ion concentration profiles for a given species in cement paste specimens. As other studies the model succeeded in calculating the position of the ettringite precipitation front and the position of the first decrease due to the portlandite dissolution whereas the leaching of portlandite and ettringite was not accurately assessed in the first millimeters because of the necessity to take into account change of the transport properties in the degraded zone. Then a numerical parametric study was carried on. The influence of permanent solution renewal, $\mathrm{pH}$ control, and dissolved $\mathrm{CO}_{2}$ concentration were analyzed. The accelerating effect of permanently renewing the solution was confirmed. The influence of the $\mathrm{pH}$ control was found dependent of the renewing of solution. The presence of $\mathrm{CO}_{2}$ did not play a significant role.
\end{abstract}

\section{Introduction}

The presence of sulfate in groundwater affects the durability of cement-based materials. Sulfate propagates into the material and modifies transport and mechanical properties, which is called External Sulfate Attacks (ESA). Even after the complete hydration of cement paste the interstitial solution of mortar or concrete is actually in a metastable thermodynamic equilibrium with the various solid phases. The ingress of external sulfate changes the chemical composition of the interstitial solution and disturbs the local thermodynamic equilibrium. Then dissolution and precipitation reactions might occur. Dissolution of hydration products mainly affects Portlandite $\mathrm{Ca}(\mathrm{OH})_{2}$. The increase of sulfate concentration in interstitial solution results in the formation of ettringite $\left(\mathrm{C}_{3} \mathrm{~A} \cdot 3 \mathrm{CaSO}_{4} \cdot 26 \mathrm{H}_{2} \mathrm{O}-\mathrm{AFt}\right)$. The leaching of portlandite and

\footnotetext{
* Corresponding author.

E-mail address: ahmed.loukili@ec-nantes.fr (A. Loukili).
}

ettringite crystallization pressure cause an increase in porosity, expansion, cracking, and consequently a loss of mechanical properties and an increase in permeability. The usual way of preventing ESA is to reduce $C_{3} A$ and $C_{3} S$ contents. Mineral admixtures such as slag and fly ash are often used to improve the durability of cement-based materials exposed to sulfate attacks. The mineralogical composition of mineral admixtures is likely to vary, resulting in different levels of resistance to external sulfate attacks, but common mechanisms can be observed. Low-calcium fly ash and slag act at three different levels. As the Portland cement content is reduced, the $\mathrm{C}_{3} \mathrm{~A}$ content, and the initial $\mathrm{Ca}(\mathrm{OH})_{2}$ content provided by the hydration of cement, are lower. The hydration of slag and the pozzolanic reaction consume $\mathrm{Ca}(\mathrm{OH})_{2}$ in cementitious matrix. Such reactions produce denser hydration products, such as CSH, thus lower permeability. Our study mainly deals with Portland cement but other works explain how supplementary cementitious materials such as fly ash and slag influence the resistance of concrete to sulfate attack $[1,2]$. Other studies have shown that the 
influence of fly ash and slag on sulfate resistance depends on exposure conditions, for instance, the nature of the associated cation (e.g., $\mathrm{Mg}^{2+}, \mathrm{Ca}^{2+}, \mathrm{Na}^{+}$) [3] and wetting and drying cycles [4]. As a consequence it is necessary to understand the influence of exposure conditions on chemical and physical phenomena involved in sulfate attacks to design reliable tests.

ESA have been studied for a long time. Laboratory testing procedures have been carried out to compare the resistance of cementbased materials to ESA. It is often assumed that performance and service life correlate with indicators deduced from short-term accelerated tests. Acceleration can result from increasing sulfate concentration, increasing temperature, decreasing $\mathrm{pH}$ [5] or applying an external electrical field [6]. Nevertheless, the representativity of these tests is still discussed [7]. One reason can be the large number of factors that can influence not only the degradation rate but also the mechanism of degradation. Another reason is that factors can depend on each other. Moreover the indicators deduced from sulfate attack testing mainly deal with mechanical and physical behavior, namely: expansion, strength, elastic modulus, and permeability. However the same physical degradation, for instance cracking or increase in permeability can be due to several mechanisms of degradation.

There are several number of studies dealing with thermodynamic modeling coupled with transport models for describing sulfate attack and its consequences in terms of precipitation/ dissolution of mineral phases [8,9]. Marchand et al. described the theory of the coupling procedure [8]. Other studies focused on comparisons between numerical results and experimental data [10-12]. Some interested in the choice of the transport equations and concluded that a Nernst-Planck description for the transport of the species seems to be a good choice $[10,13]$ or at least a multi-species fickian approach [10]. Today, it seems to be interesting to propose a parametrical study of such a coupled model in order to improve its behavior and to show the necessity or not to take into account several conditions (e.g. renewal of the aggressive solution, presence of dissolved $\mathrm{CO}_{2}$ in the solution, control of the solution $\mathrm{pH}$ ).

This study aims at contributing to understand the complex mechanisms that drive ESA during sulfate attack testing in controlled exposure conditions [14]. A chemical transport coupling numerical model has been used on simple procedure [15]. The model have been modified and intended for ESA problems in this work. Simulations might also have been performed by other coupling software as Hytec [16] or ToughReact [17]. Nevertheless, the softwares used in the present coupling procedure and in particular Comsol gives the possibility to include the material mechanical behavior for further studies.

Numerical results actually show changes in chemical species concentrations and dissolution/precipitation fronts inside the material that are difficult to assess experimentally. However recent developments in SEM-EDX technique and X-ray microtomography provide useful information dealing with chemical changes in cement paste. Moreover the sulfate attack testing presented in this study allows determining the amounts of calcium and sulfate ions that are leached or ingress in the cement paste specimens.

This paper first presents a comparison between total concentrations of calcium, aluminium and sulfur ( $\mathrm{Ca}, \mathrm{Al}$ and $\mathrm{S}$ ) profiles deduced from SEM-EDX and simulated by the model. Then a numerical parametric study is proposed to quantify the different factors influencing sulfate ingress, precipitation of phases or dissolution rates. Three parameters have been studied. The first one is the effect of renewing the sulfate solution [9]. The experimental procedure actually ensures that the solution is renewed at regular intervals. The numerical model aims to quantify this effect. The second parameter is the $\mathrm{pH}$, which can be controlled or not by adding nitric acid. This latter quantity is actually assumed to be directly related to the amount of calcium leached from the cement paste, as it is the case for calcium leaching in pure deionized water [18]. Previous study has underlined the importance of controlling the $\mathrm{pH}$ on the degradation rate $[9,19]$. The third one is the influence of dissolved $\mathrm{CO}_{2}$ in samples immersing solution. The solution is generally in equilibrium with atmospheric pressure and air with $\mathrm{CO}_{2}$.

The simulation is viewed here as another kind of experimental system and should be analyzed as such. That is to say that, the model is tested to define its reliability and, if successful, it is considered to provide understanding of the modeled phenomena. For this purpose, Section 2 describes the experimental procedure. In Section 3, the model and hypotheses are exposed, including the chosen cement paste hydration composition and adopted transport equations. Results are then compared to experimental data in Section 4. Finally, the numerical parametric study is presented.

\section{Experimental procedure}

\subsection{Sulfate attack testing}

The test was conducted on Portland cement paste with a water/cement ratio of 0.4 . The chemical composition of cement is given in Table 1.

Two cement paste samples were immersed for at least 160 days in a $\mathrm{Na}_{2} \mathrm{SO}_{4}$ solution (3 g/L sulfate concentration), as shown in Fig. 1 [20]. The cylindrical specimens were $160 \mathrm{~mm}$ high and $20 \mathrm{~mm}$ in diameter. They were coated on their both ends with a water-proof vinylester resin, thus exposed to sulfate attack only on their circumferential surfaces. They were immersed in $1.7 \mathrm{~L}$ sodium sulfate solution tank after 28 days of water curing.

As $\mathrm{pH}$ tended to increase because of the dissolution of portlandite $\mathrm{Ca}(\mathrm{OH})_{2}$, $0.5 \mathrm{~mol} / \mathrm{L}$ nitric acid was added to control the $\mathrm{pH}$ of the sulfate solution at a constant value $\mathrm{pH}=7.5$. The solution was renewed every $15 \mathrm{~mL}$ of added nitric acid Its calcium and sulfate concentrations were determined using ionic chromatography.

\subsection{Microtomography}

XRadia MicroXCT-400 system was used to observe samples after 160 days of sulfate attack. The energy used was $110 \mathrm{kVp}$ X-rays. Successive rotations of the sample, 2000 projections, corresponding to 2000 angular positions ranging between 0 and 360 , were acquired by a 4 megapixel $(2048 \times 2048)$ CCD-digital camera and an objective revolver, that can be used to choose the desired magnification. Filters were used to compensate for beam hardening. The pixel size was $28 \mu \mathrm{m}$ and the exposure time was $4 \mathrm{~s}$ for each image. The data scanned with the Xradia device was reconstructed with Xradia's own software.

\subsection{Scanning Electron Microscopy}

SEM investigation was used to analyze the micro-structure of the sulfate attacked specimens. The Jeol JSM-6060 LA microscope was also equipped with an energy dispersed X-ray analysis and X-ray Mapping. The observations were performed by back-scattered electrons imaging. The pressure in the specimen chamber was $50 \mathrm{~Pa}$ and the accelerating voltage was $15 \mathrm{kV}$. The specimens used for SEM observations were $3 \mathrm{~cm}$ thick slices from the $2 \times 2 \times 16 \mathrm{~cm}^{3}$ mortar prisms. They were dried for two days at $20 \mathrm{C}, 50 \%$ H.R and then embedded in a low modulus epoxy resin. The specimens were then polished using progressively finer grids.

Table 1

Chemical composition of CEMI 52,5N CE CP2 NF cement.

\begin{tabular}{lc}
\hline Oxide & Quantity (wt.\%) \\
\hline $\mathrm{SiO}_{2}$ & 20.6 \\
$\mathrm{Al}_{2} \mathrm{O}_{3}$ & 5.3 \\
$\mathrm{Fe}_{2} \mathrm{O}_{3}$ & 2.11 \\
$\mathrm{CaO}$ & 66.3 \\
$\mathrm{MgO}$ & 1.09 \\
$\mathrm{~K}_{2} \mathrm{O}$ & 0.28 \\
$\mathrm{Na}_{2} \mathrm{O}$ & 0.18 \\
$\mathrm{SO}_{3}$ & 3.3 \\
Other & 0.84 \\
\hline
\end{tabular}




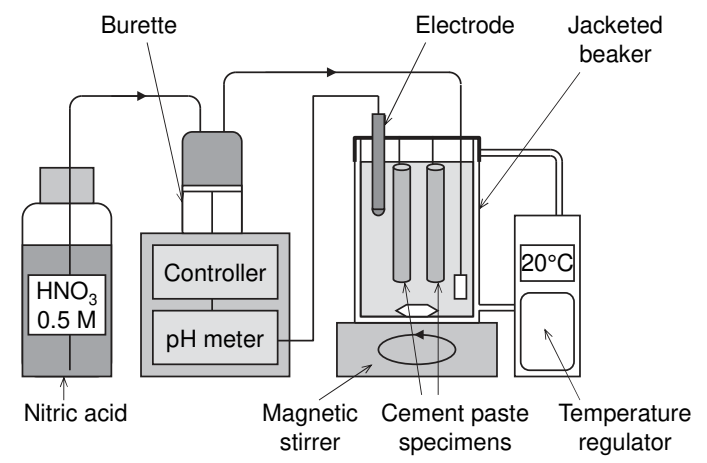

Fig. 1. External sulfate attack testing.

\section{Modelling}

\subsection{Cement paste hydration}

The cement paste hydration was modeled using a minimization method from BRGM (Bureau de Recherches Géologiques et Minières), the French Geological Survey. Results are presented in Table 2, for a 0.4 water cement ratio.

The database Thermoddem [21] was used in order to obtain the hydrated phases. The CSH was assumed to be a single phase gel as the complex form is still discuss in the literature. The monosulfate is not present because of a recent paper [22] mentioned that it is stable only between $65^{\circ} \mathrm{C}$ and $121^{\circ} \mathrm{C}$. For the present study, the database Thermoddem supplied with data from "cemdata 2007" [23] was also used thereafter for the geochemical model. Table 3 shows a part of the database where the mineral phases were supposed to react. The choice of these solids were motivated by a report from Jacques where the solid composition of an OPC concrete in the $\mathrm{CaO}-\mathrm{SiO}_{2}-\mathrm{Al}_{2} \mathrm{O}_{3}-\mathrm{Fe}_{2} \mathrm{O}_{3}-\mathrm{MgO}-\mathrm{SO}_{3}-\mathrm{CO}_{2}$ system during sulfate attack [24] and previous work where mineral phases that were dissolved and precipitated were quite similar [12].

BRGM hydration calculation does not give the composition of the cement paste pore solutio. From the hydration results, the next step consisted in finding the concentration of elements in the interstitial solution by calculating the equilibrium with solid phases (cf. Table 4). This was done with PHREEQC, which is a computer program for speciation, batch-reaction, one dimensional transport, and inverse geochemical calculations [25]. The calculated $\mathrm{pH}$ was equal to 13.16 . The results obtained from equilibrium showed very few differences in phase contents compared to BRGM hydration results $(<1 \%)$. Hence, the hydration calculation was assumed to be thermodynamically correct.

\subsection{Reactive transport modeling}

\subsubsection{Transport}

By considering in this study samples immersed in $\mathrm{Na}_{2} \mathrm{SO}_{4}$ solution, diffusion is supposed to be the main transport phenomena. A pure multi-species fickian diffusion model is chosen. It is preferred to a Nernst-Planck approach at least because Samson and Marchand [10] actually showed that the results with or without an electrical potential for similar simulation are very closed. The main differences are the verification or not of the electroneutrality. In our multispecies fickian approach, the electroneutrality is not verified but we assumed that it is obtained with the chemical part of the model (speciation, precipitation/dissolution every $1800 \mathrm{~s}$, see below). The sorption phenomena is considered to be purely chemical (ie. no physical adsorption or absorption) and modeled by the geochemical part of the simulation. The governing equation is then:

$\frac{\partial c_{i}}{\partial t}=D_{e, i} \Delta c_{i}$

where $c_{i}$ is the concentration of the species $i$ (in $\mathrm{mol} \mathrm{m}^{-3}$ of solution), $D_{e, i}$ the effective ionic diffusion coefficient in the porous media (in $\mathrm{m}^{2} \mathrm{~s}^{-1}$ ) and $\Delta$ the divergence operator.

\subsubsection{Transport data}

The effective diffusion coefficient of species $i$ in cement paste, $D_{e, i}$, is considered as a function of tortuosity, $\tau$, porosity, $\theta$ and pure diffusion coefficient of species $i$ in water, $D_{w, i}$ :

$D_{e, i}=\tau \theta D_{w, i}$

In previous works $[8,11]$, several effective diffusion coefficients were measured for different species on cement paste (OPCs with a $0.4 \mathrm{w} / \mathrm{c}$ ratio). The ratios between diffusion coefficients in cement paste and in water for each species were equal $\left(\sim 6.6 \times 10^{-3}\right.$ for $\langle\langle$ CSA type 10$\rangle\rangle$ and $\sim 11 \times 10^{-3}$ for $\langle\langle$ CSA type 50$\rangle\rangle$ [11]). This ratio is equal to the product between tortuosity and porosity in the present study (see Eq. (2)). It is then possible to deduce diffusion coefficient for each species in cement paste from one measurement. Nevertheless, no diffusion coefficient measurement was done. According to previous work [26] that studied several diffusion coefficient values of chloride as a function of water/cement ratio, the diffusion coefficient of chloride for the present hydrated cement pastes was chosen equal to $3.4 \times 10^{-12} \mathrm{~m}^{2} \mathrm{~s}^{-1}$, which leads to a tortuosity value of $9 \times 10^{-3}$ (see Eq. (2)). The product between tortuosity and porosity was assumed to be constant. Given the diffusion coefficient values of the different species in water (cf. Table 5), the diffusion coefficient for all species in cement paste was deduced from Eq. (2).

\subsubsection{Coupling procedure}

The authors used a procedure developed by Wissmeier et al. [15]. The solute transport part is calculated by COMSOL $^{\circledR}$ [28]. The geochemical reactions are calculated by PHREEQC [29]. More specifically, the geochemical part is solved by IPHREEQC [30] which is a Microsoft COM (component object model) that has been implemented and which allows PHREEQC to be used by any software that can interface with a COM server, as Matlab ${ }^{\circledR}$ [31]. Hence, Matlab $^{\circledR}$ is the controlling application and the interface for the COMSOL and Iphreeqc modules. The PHREEQC one-dimensional transport capabilities were not used in this work because of their limits. Although PHREEQC can simulate a multi-species transport with a diffusion coefficient for each species, it cannot model two

Table 2

Hydration results of CEM1 52,5N CE CP2 NF.

\begin{tabular}{|c|c|c|c|c|}
\hline Phase & Formulation & Quantity [mol $/ \mathrm{dm}^{3}$ of solid] & Species & Quantity [mol/l of solution] \\
\hline $\mathrm{C}_{3} \mathrm{FH}_{6}$ & $\mathrm{Ca}_{3} \mathrm{Fe}_{2}(\mathrm{OH})_{12}$ & $7.83 \times 10^{-1}$ & $\mathrm{Cl}$ & $3.3 \times 10^{-2}$ \\
\hline $\mathrm{CSH}(1.6)$ & $\mathrm{Ca}_{1.6} \mathrm{SiO}_{3.6}: 2.58 \mathrm{H}_{2} \mathrm{O}$ & $1.85 \times 10^{1}$ & $\mathrm{~K}$ & $1.2 \times 10^{-1}$ \\
\hline Ettringite & $\mathrm{Ca}_{6} \mathrm{Al}_{2}\left(\mathrm{SO}_{4}\right)_{3}(\mathrm{OH})_{12}: 26 \mathrm{H}_{2} \mathrm{O}$ & $8.14 \times 10^{-1}$ & $\mathrm{Na}$ & $1.1 \times 10^{-1}$ \\
\hline Hydrotalcite & $\mathrm{Mg}_{4} \mathrm{Al}_{2} \mathrm{O}_{7}: 10 \mathrm{H}_{2} \mathrm{O}$ & $4.01 \times 10^{-1}$ & & \\
\hline KatoiteSi1 & $\mathrm{Ca}_{3} \mathrm{Al}_{2}\left(\mathrm{SiO}_{4}\right)(\mathrm{OH})_{8}$ & 1.87 & & \\
\hline Portlandite & $\mathrm{Ca}(\mathrm{OH})_{2}$ & $2.77 \times 10^{1}$ & & \\
\hline
\end{tabular}


Table 3

Thermodynamic properties at $25^{\circ} \mathrm{C}$ for solids present in cements from Thermoddem [21], supplied with data from "cemdata2007" [23].

\begin{tabular}{|c|c|c|}
\hline Mineral & $\log (K)$ & Refs. \\
\hline $\mathrm{C}_{2} \mathrm{AH}_{8}+12 \mathrm{H}^{+} \rightarrow 3 \mathrm{Ca}^{2+}+2 \mathrm{Fe}^{3+}+12 \mathrm{H}_{2} \mathrm{O}$ & -13.5622 & [23] \\
\hline Calcite $+\mathrm{H}^{+} \rightarrow \mathrm{HCO}_{3}^{-}+\mathrm{Ca}^{2+}$ & 1.847 & [21] \\
\hline $\mathrm{CSH}(1.6)+3.2 \mathrm{H}^{+} \rightarrow 1.6 \mathrm{Ca}^{2+}+\mathrm{H}_{4} \mathrm{SiO}_{4}+2.18 \mathrm{H}_{2} \mathrm{O}$ & 28.002 & {$[21]$} \\
\hline Ettringite $+12 \mathrm{H}^{+} \rightarrow 2 \mathrm{Al}^{3+}+6 \mathrm{Ca}^{2+}+3 \mathrm{SO}_{4}^{2-}+38 \mathrm{H}_{2} \mathrm{O}$ & 57.009 & {$[21]$} \\
\hline Gypsum $\rightarrow \mathrm{Ca}^{2+}+\mathrm{SO}_{4}^{2-}+2 \mathrm{H}_{2} \mathrm{O}$ & -4.605 & {$[21]$} \\
\hline Hydrotalcite $+14 \mathrm{H}^{+} \rightarrow 2 \mathrm{Al}^{3+}+4 \mathrm{Mg}^{2+}+17 \mathrm{H}_{2} \mathrm{O}$ & 73.757 & {$[21]$} \\
\hline KatoiteSi $1+12 \mathrm{H}^{+} \rightarrow 2 \mathrm{Al}^{3+}+3 \mathrm{Ca}^{2+}+\mathrm{H}_{4} \mathrm{SiO}_{4}+8 \mathrm{H}_{2} \mathrm{O}$ & 71.168 & {$[21]$} \\
\hline Monocarboaluminate $+13 \mathrm{H}^{+} \rightarrow 2 \mathrm{Al}^{3+}+\mathrm{HCO}_{3}^{-}+4 \mathrm{Ca}^{2+}+16.68 \mathrm{H}_{2} \mathrm{O}$ & 80.567 & {$[23]$} \\
\hline Portlandite $+2 \mathrm{H}^{+} \rightarrow \mathrm{Ca}^{2+}+2 \mathrm{H}_{2} \mathrm{O}$ & 22.812 & [21] \\
\hline Tricarboaluminate $\rightarrow 6 \mathrm{Ca}^{2+}+2 \mathrm{Al}(\mathrm{OH})_{4}^{-}+3 \mathrm{CO}_{3}^{2-}+4 \mathrm{OH}^{-}+26 \mathrm{H}_{2} \mathrm{O}$ & -46.5085 & [23] \\
\hline
\end{tabular}

Table 4

Equilibrium phases results with PHREEQC.

\begin{tabular}{|c|c|c|c|c|}
\hline Phase & Formulation & Quantity [mol $/ \mathrm{dm}^{3}$ of solid] & Species & Quantity [mol/l of solution] \\
\hline $\mathrm{C}_{3} \mathrm{FH}_{6}$ & $\mathrm{Ca}_{3} \mathrm{Fe}_{2}(\mathrm{OH})_{12}$ & $7.83 \times 10^{-1}$ & $\mathrm{Al}$ & $2.16 \times 10^{-4}$ \\
\hline $\mathrm{CSH}(1.6)$ & $\mathrm{Ca}_{1.6} \mathrm{SiO}_{3.6}: 2.58 \mathrm{H}_{2} \mathrm{O}$ & $1.85 \times 10^{1}$ & $\mathrm{Ca}$ & $2.06 \times 10^{-3}$ \\
\hline Ettringite & $\mathrm{Ca}_{6} \mathrm{Al}_{2}\left(\mathrm{SO}_{4}\right)_{3}(\mathrm{OH})_{12}: 26 \mathrm{H}_{2} \mathrm{O}$ & $8.14 \times 10^{-1}$ & $\mathrm{Cl}$ & $3.33 \times 10^{-2}$ \\
\hline Hydrotalcite & $\mathrm{Mg}_{4} \mathrm{Al}_{2} \mathrm{O}_{7}: 10 \mathrm{H}_{2} \mathrm{O}$ & $4.01 \times 10^{-1}$ & $\mathrm{Fe}$ & $4.57 \times 10^{-7}$ \\
\hline KatoiteSi1 & $\mathrm{Ca}_{3} \mathrm{Al}_{2}\left(\mathrm{SiO}_{4}\right)(\mathrm{OH})_{8}$ & 1.87 & $\mathrm{~K}$ & $1.21 \times 10^{-1}$ \\
\hline \multirow[t]{4}{*}{ Portlandite } & $\mathrm{Ca}(\mathrm{OH})_{2}$ & $2.77 \times 10^{1}$ & $\mathrm{Mg}$ & $9.73 \times 10^{-10}$ \\
\hline & & & $\mathrm{Na}$ & $1.11 \times 10^{-1}$ \\
\hline & & & $\mathrm{S}$ & $5.2 \times 10^{-4}$ \\
\hline & & & $\mathrm{Si}$ & $1.11 \times 10^{-4}$ \\
\hline
\end{tabular}

Table 5

Diffusion coefficient values in water [27].

\begin{tabular}{|c|c|c|c|c|c|c|c|c|c|c|c|c|c|}
\hline Species & $\mathrm{Al}$ & C & $\mathrm{Ca}$ & $\mathrm{Cl}$ & $\mathrm{Fe}$ & $\mathrm{H}$ & K & $\mathrm{Mg}$ & $\mathrm{N}$ & $\mathrm{Na}$ & $\mathrm{O}$ & $\mathrm{S}$ & $\mathrm{Si}$ \\
\hline $\mathrm{Dw}\left(\times 10^{-9}\right)$ & 0.346 & 0.78 & 0.673 & 1.71 & 0.582 & 4.49 & 1.67 & 0.594 & 0.594 & 1.13 & 4.49 & 0.89 & 0.7 \\
\hline
\end{tabular}

zones with different transport properties (ie. cement paste and $\mathrm{Na}_{2} \mathrm{SO}_{4}$ solution).

At each time step, main species solute transport is computed and the data from the output of one procedure is passed back to the other. The coupling procedure is a non-iterative sequential split-operator approach. The coupling time step is further reduced within the iterative schemes for solute transport and geochemical speciation as required by the respective software algorithms. As in a previous study [10], the homogeneous reactions that are those occurring solely in the aqueous phase, are neglected in the present model. Only the heterogeneous reactions (dissolution/precipitation essentially) which allow to eliminate the source/sink terms of the model are considered.

The geochemical reactions rate was supposed to be large with respect to the ionic and fluid transport processes. In this particular case, the local chemical equilibrium was assumed to be preserved throughout the porous system. This hypothesis is usually valid in most practical cases involving the diffusion of ions in fluid saturated systems [10,32].

\subsection{Parameters of numerical simulations}

For symmetry reasons, the problem is considered as onedimensional. The dimension of the mesh of volume containing the $\mathrm{Na}_{2} \mathrm{SO}_{4}$ solution perpendicular to the exposed surface was estimated as previous work [12]. Given the experimental liquid/solid volume ratio of 33.82 to 1 , and since the volume of the specimen was $1.7 \mathrm{~L}$, the ratio of the volume containing the $\mathrm{Na}_{2} \mathrm{SO}_{4}$ solution over specimen surface was $16 \mathrm{~cm}$. This length corresponded then to the sought dimension of the batch perpendicular to the specimen surface. The sample was modeled numerically by 150 linear finite elements with a refinement zone within the firsts cement paste millimeters where precision is needed. Time step was equal to $1800 \mathrm{~s}$ and leads to at least $48 \mathrm{~h}$ total computation time. This time step ensures the convergence of the solution since it is quite small to preserve thermodynamic equilibrium and large enough to overcome the kinetics. In order to model the influence of the effect of the magnetic stirrer on the $\mathrm{Na}_{2} \mathrm{SO}_{4}$ solution, the diffusion coefficients of all species in water are arbitrarily multiplied by 1000 .

\section{Comparison between experimental data and numerical results}

It is often difficult to compare quantitatively experimental and simulation results. On the one hand, experimental studies provide concentrations in the immersing solution or analysis of very localized parts of the sample, from microscopy for example. On the other hand, numerical results show concentration species or phases in the sample as a function of depth and time. Now, it is possible to measure the evolution of the total quantity of chemical elements such as calcium Ca as a function of depth with the SEMEDX technique. Experimental results were deduced from three EDX analysis on the same section observed in SEM. Fig. 2 shows numerical results after 160 days of sulfate exposure. The results are very similar to other studies that predicted two dissolution fronts of the portlandite and a position of the first front of the portlandite that corresponded to the precipitation front of the ettringite $[11,12]$.

Figs. 3 and 4 show the comparison between experimental data at 160 days and numerical results. Here, the model chosen had parameters that were assumed to be the most representative with regard to the experimental study, namely: the $\mathrm{Na}_{2} \mathrm{SO}_{4}$ solution was in equilibrium with $\mathrm{CO}_{2}$, the $\mathrm{pH}$ was constant and equal to 7.5 and the sulfate concentration in solution was constant. 


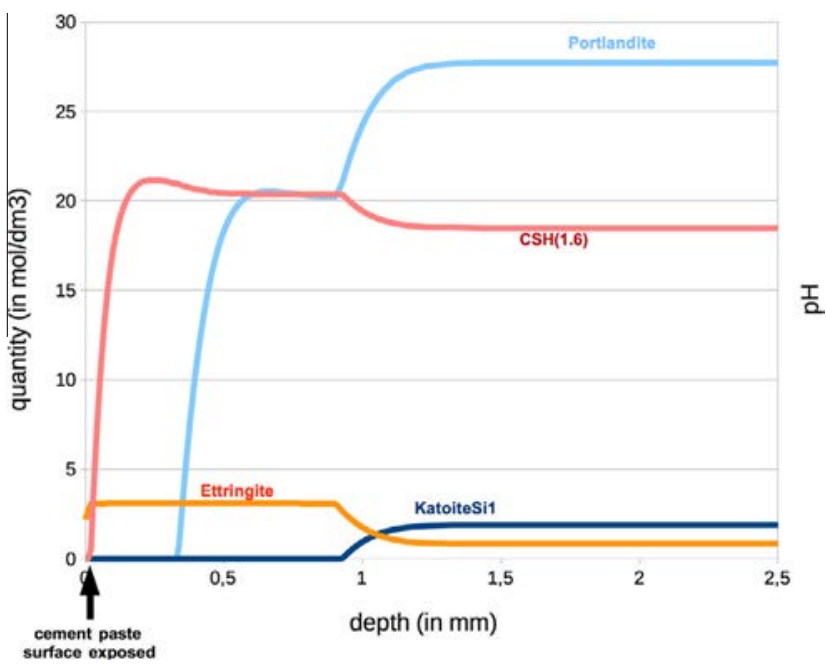

Fig. 2. Numerical results after 160 days of exposure.

The numerical simulation succeeded in predicting the position of the total sulfate front in the material which corresponds to the ettringite precipitation front and the position of the first decrease due to the portlandite dissolution but failed evaluating the maximum sulfate content in the first millimeters. Moreover, the measured depth reached by the leaching of calcium, which corresponds to the second portlandite dissolution front, was deeper than the model predictions as can be seen in previous study [12]. Finally, the measured calcium content gradually decreases in the degraded zone whereas the numerical dissolution curve decreases much faster.

The results show that the problem essentially comes from the fact that the dissolution of ettringite in the degraded zone is not well taken into account in this model and the others [11,12]. In the degraded zone the dissolution rates are actually faster and lead to a faster dissolution of the minerals, especially for ettringite created earlier $[33,34]$. Indeed, the fitted values of total S amount in Fig. 3 (black dashed line) that corresponds to the quantity of ettringite in the degraded zone leads to a better estimation of Ca content (see Fig. 2). One way to avoid such a problem in the simulation is to actualize the transport properties evolutions due to degradation as can be seen in Fig. 5. The growth of ettringite crystals due to supersaturation of sulfate generates crystallization pressure. This results in expansion then cracking of cementitious matrix. Leaching and cracking favor the ingress of sulfate concentrated solution and accelerates the degradation. Ref. [35] used ultrasonic tests to determine the evolution of damage in concrete exposed to sulfate attacks. This coupling between chemical and mechanical damage and the ingress of sulfate ions has been taken into account in other models [36]. The ratio of sulfate diffusion coefficient of cracked concrete to that of sound concrete has actually a significant influence on the kinetics of degradation and linear expansion [2,37].

Other minor aspects can also explained the differences, namely:

- SEM-EDX analysis and microtomography provide local data that are likely to depend on the observed section, whereas perfect symmetry is assumed in numerical simulations. Only one experimental profile per element is presented in Figs. 2 and 3. Differences between experimental data and simulation could come from significant dispersion of experimental data, as shown on pictures from microtomography (see Fig. 5).

- Accurate assessment of the pore solution $\mathrm{pH}$ is difficult for the numerical model, as previously highlighted [15]. Ettringite is known to be unstable below a pH around 10.5 [38]. A slightly lower $\mathrm{pH}$ value in the first millimeter would actually increase the leaching of ettringite and $\mathrm{CSH}$, thus a lower Ca content;

- The numerical model does not actualize the transport properties due to the porosity evolution and cracks propagation.

Although experimental data and numerical results can be quantitatively different in the degradated zone for the reasons exposed before, the model was used to predict the influence of several parameters of boundary conditions on the dissolution and precipitation of phases. The simulations presented thereafter were used to discuss the representativeness of laboratory external sulfate attack testing.

\section{Numerical parametric study}

\subsection{Influence of boundary conditions}

Two boundary conditions have been tested: a continuous sulfate solution inflow at the edge of the solution and no flux. The first condition simulates a permanently renewed solution whereas the second corresponds to a solution which is never renewed.

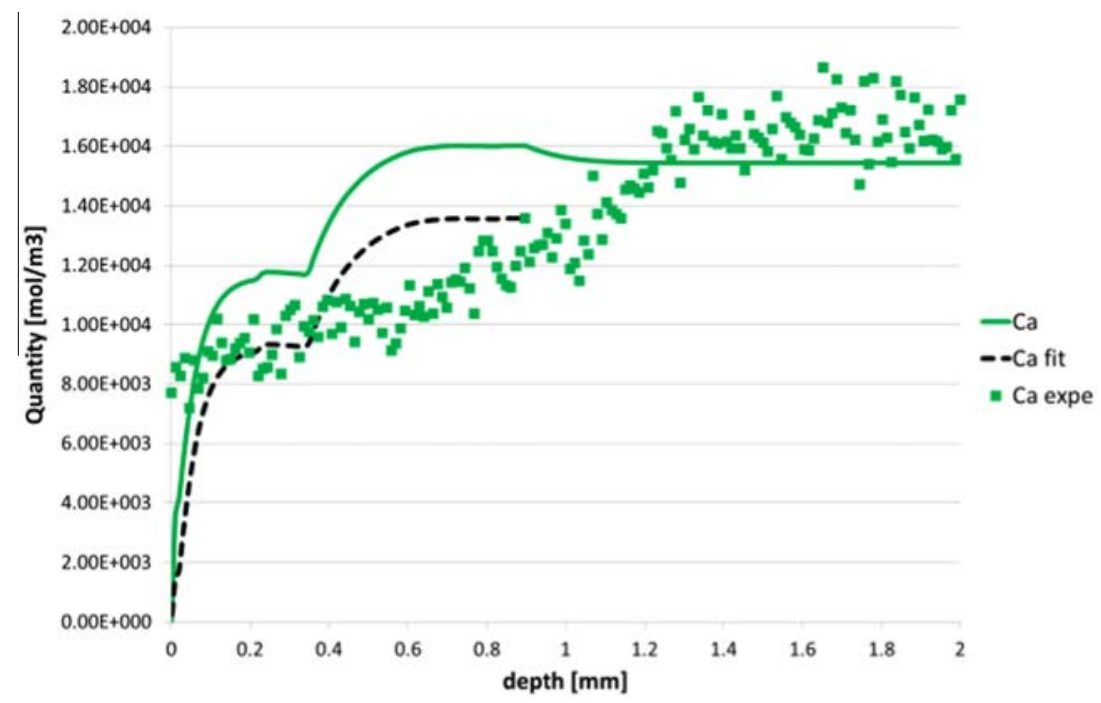

Fig. 3. Comparison between experimental, numerical (solid line) and numerical fit (dashed line) total Ca profile after 160 days of exposure. 


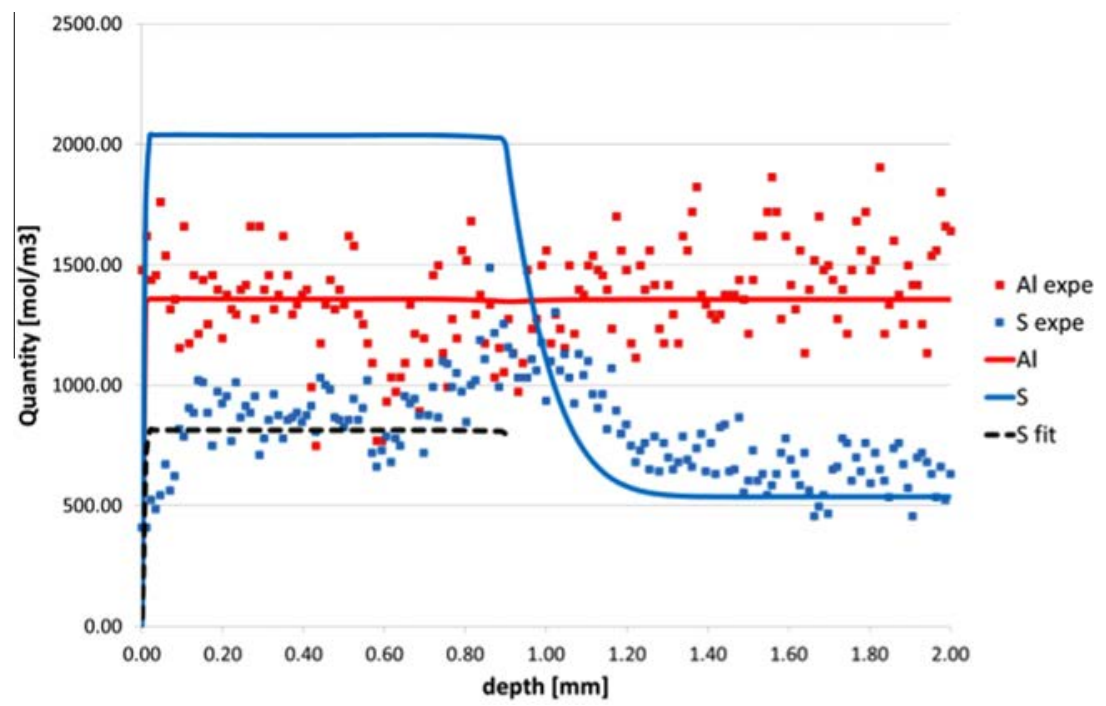

Fig. 4. Comparison between experimental, numerical (solid line) and numerical fit (dashed line) total Al and S profiles after 160 days of exposure.
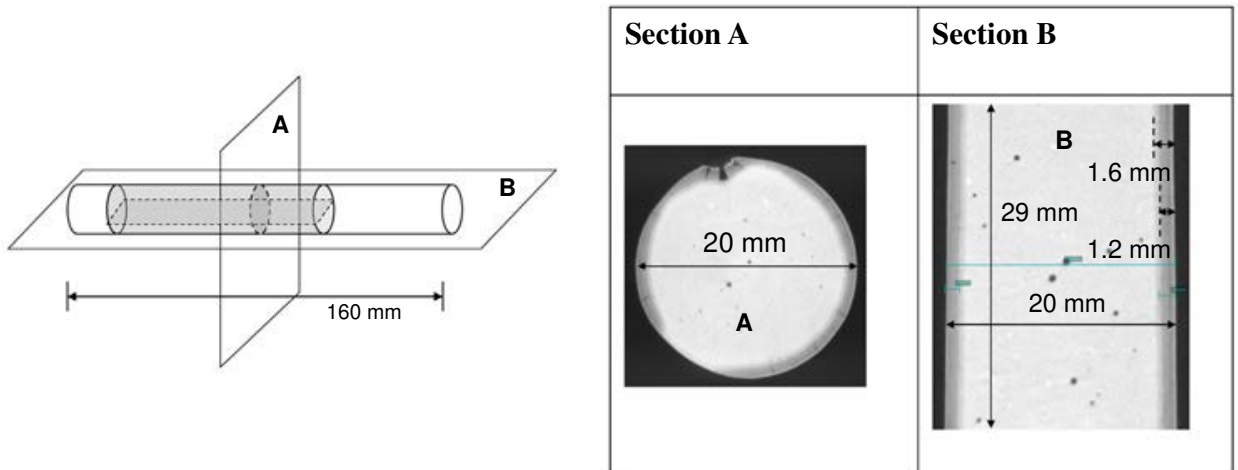

Fig. 5. Sections from X-ray microtomography (Left) - Pictures from X-ray microtomography (Right).

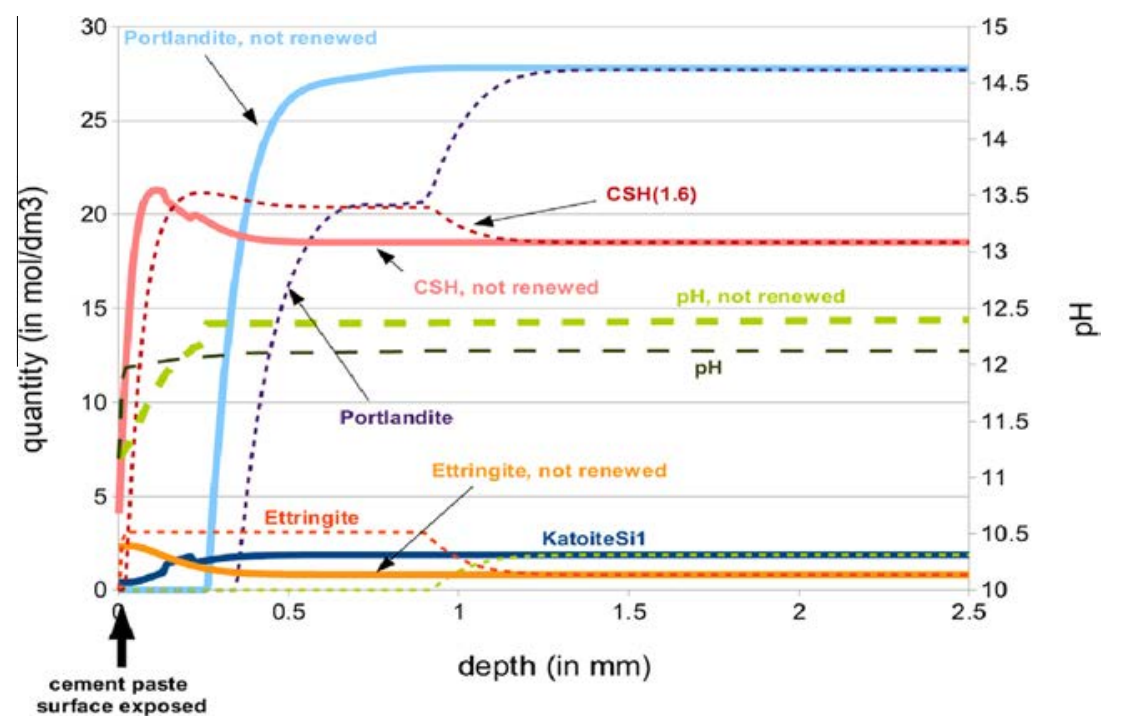

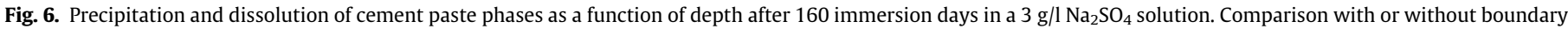
conditions.

Fig. 6 shows significant differences between the two series of results. If the solution is not renewed the portlandite dissolution front ingress is much slower although the $\mathrm{pH}$ is not very different.
Moreover, the ettringite precipitation is much lower. This effect can be explained by plotting the sulfate concentration in the sodium sulfate solution and in the interstitial solution (negative 


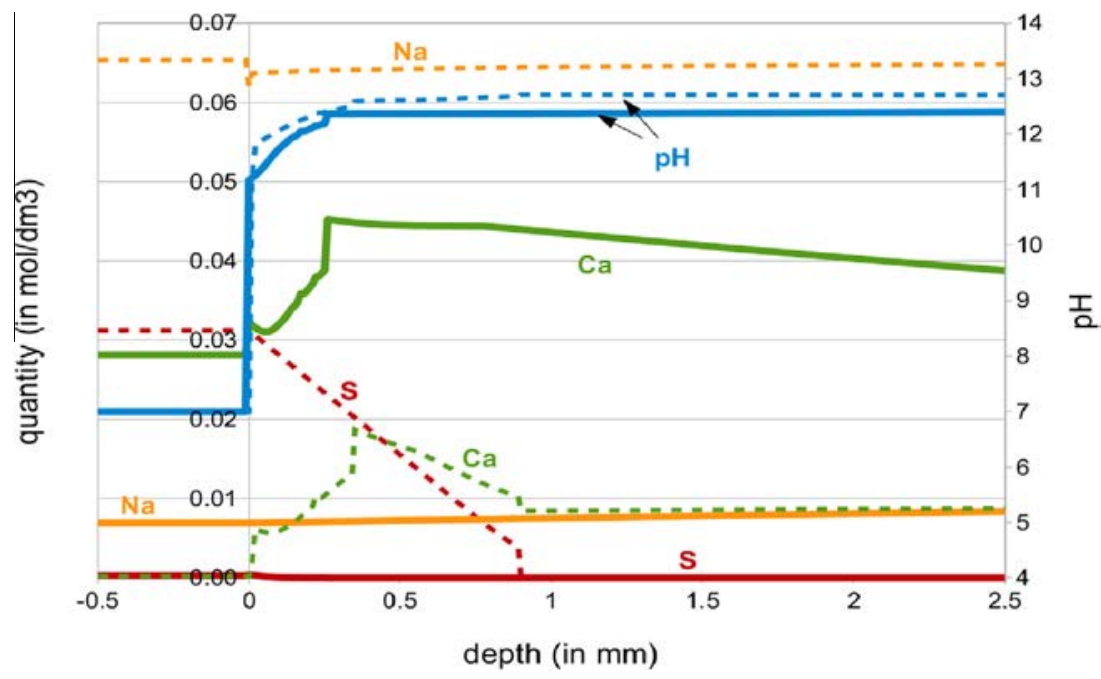

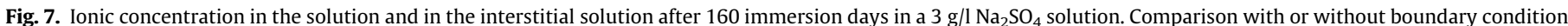
(dashed line and plain line, respectively).

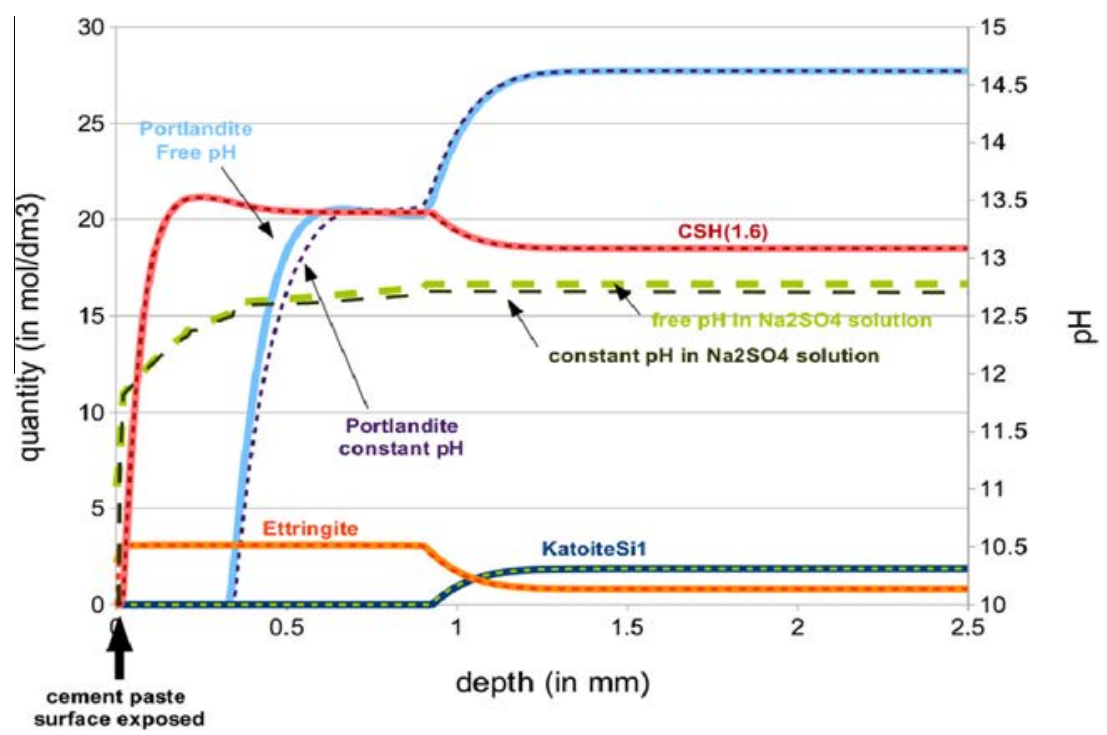

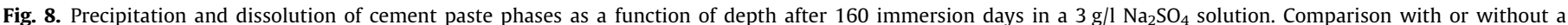
controlled $\mathrm{pH}$ in the $\mathrm{Na}_{2} \mathrm{SO}_{4}$ solution (solution renewed).

and positive $x$ values, respectively, in Fig. 7). Even for a low sample/solution volume ratio, the sulfate ions concentration decreases rapidly if the solution is not renewed.

After 160 days of immersion, the sulfate and sodium concentrations are very low and the degradation rate has significantly decreased.

\subsection{Effect of the control of the sulfate solution $\mathrm{pH}$}

If the sulfate solution is permanently renewed, the influence of $\mathrm{pH}$ control is not significant because renewing the solution participates in reducing the $\mathrm{pH}$ regularly (Fig. 8).

If the sulfate solution is not renewed and the $\mathrm{pH}$ is not controlled, numerical results showed that the $\mathrm{pH}$ increases rapidly to a value near 9 due to $\mathrm{Ca}(\mathrm{OH})_{2}$ dissolution of cement paste. The portlandite dissolution front is also deeper than for a controlled $\mathrm{pH}$ at a value of 7. The dissolution front of $\mathrm{CSH}$ is observed in the first millimeters whereas for a constant $\mathrm{pH}$ in the solution the depth of dissolution is much lower. These results confirm that the consequences of sulfate attack are different if the $\mathrm{pH}$ is not controlled and higher than 9 in the sulfate solution. This remark is of course valid if the volume of the tank in which samples are immersed is large compared to the sample volume. Cao et al. actually noted that expansion of samples decreased when the $\mathrm{pH}$ of the sulfate solution was reduced from 12 to 7 and that the expansion increased when the $\mathrm{pH}$ was reduced from 7 to 3 [19]. These results are partially confirmed in Fig. 9. If the $\mathrm{pH}$ is not controlled a layer of calcite appears in the firsts tenth of a millimeter.

\subsection{Influence of dissolved $\mathrm{CO}_{2}$ in solution}

The presence of dissolved $\mathrm{CO}_{2}$ in the solution, corresponding to a classical quantity of $\mathrm{CO}_{2}$ in the air $(0.04 \%)$ and an equilibrium between $\mathrm{CO}_{2}$ in the air and dissolved $\mathrm{CO}_{2}$ in water, in which samples are immersed does not seem to play a significant role in the geochemical behavior of the cement paste after 160 exposition days if the $\mathrm{pH}$ of the sulfate solution is maintained at a constant value $\mathrm{pH}=7$. Fig. 10 shows that the dissolution of $\mathrm{CSH}$, Portlandite 


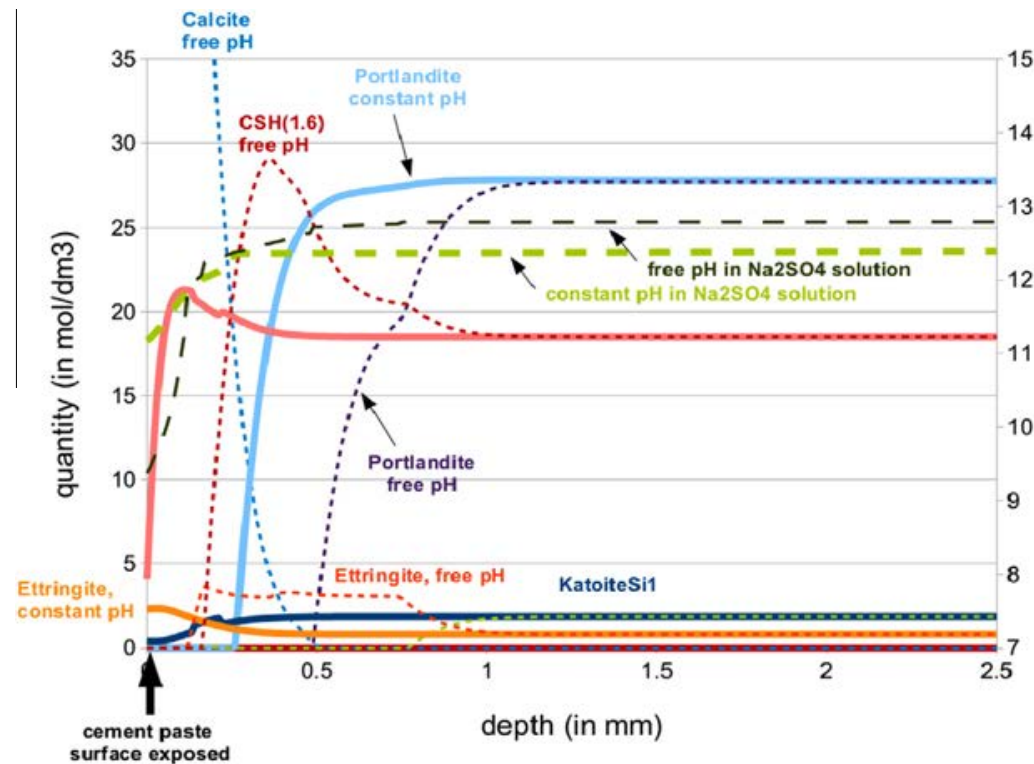

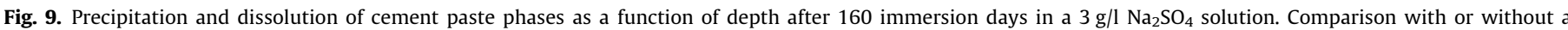
controlled $\mathrm{pH}$ in the $\mathrm{Na}_{2} \mathrm{SO}_{4}$ solution (without solution renewing).

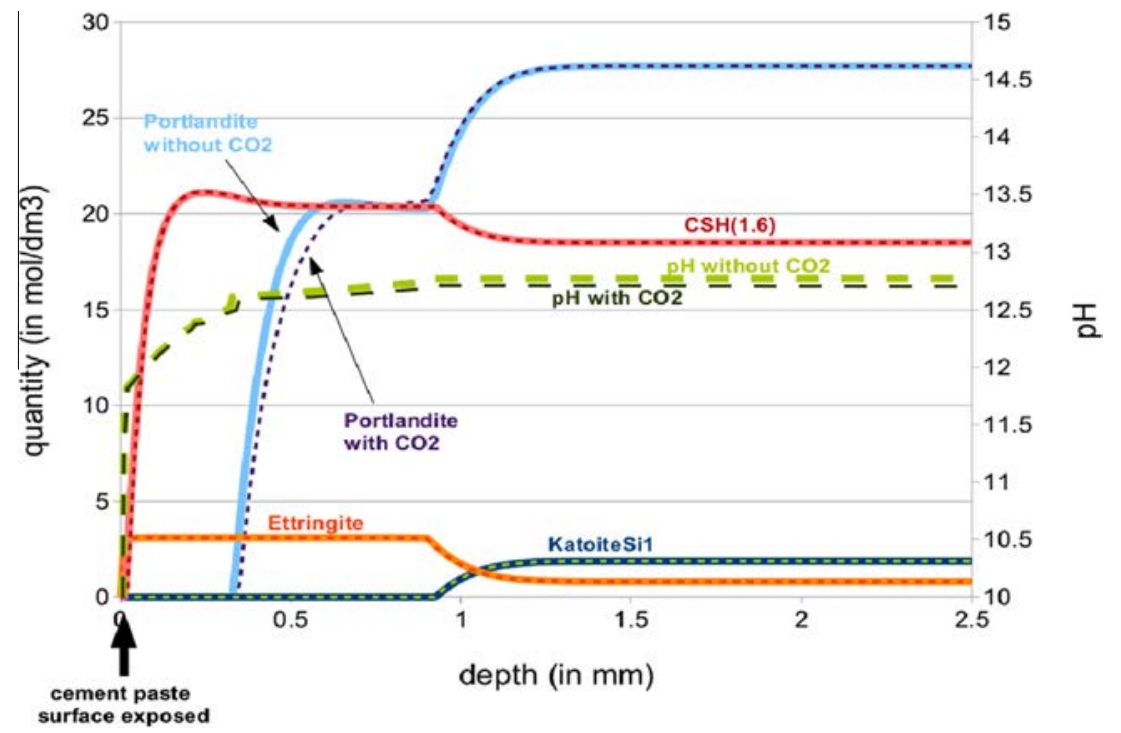

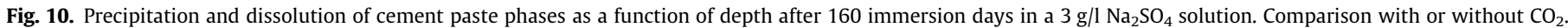

and KatoiteSi1 are very similar with or without $\mathrm{CO}_{2}$ in the solution. Even if the $\mathrm{pH}$ value is lower when the sulfate solution does contain $\mathrm{CO}_{2}$, the portlandite dissolution rate is not higher.

\section{Conclusion}

Experimental data and numerical simulations were used to improve the design of sulfate attack testing of Portland cement pastes. Sulfate attack testing consisted in exposing cement paste specimens to a $3 \mathrm{~g} / \mathrm{L}$ sodium sulfate solution. The $\mathrm{pH}$ was controlled and the sulfate solution was frequently renewed and analysed. SEM-EDX technique and X-ray microtomography were used to quantify the extent of the degradation of paste samples. A numerical coupling procedure has been tested to model the chemical degradation of the cement paste exposed to external sulfate attack. Thus experimental data and numerical simulations could be compared. Then a numerical parametric study has been exposed in order to understand the effects of several parameters that need to be taken into account when designing sulfate attack testing. Numerical results lead to the following conclusions:

- As previous studies, comparing numerical results with experimental data shows that the numerical model succeeded in predicting the ettringite precipitation front position and the position of the first decrease due to the portlandite dissolution whereas the leaching of portlandite and ettringite was not accurately assessed in the first millimeters, as most of the models proposed in the literature, because of the necessity to take into account change of the transport properties in the degraded zone; 
- Aluminate and sulfate bounded into the $\mathrm{C}-\mathrm{S}-\mathrm{H}$ have to be taken into consideration in order to understand and model the mechanism of cracks;

- The numerical parametric study showed the influence of boundary conditions on the degradation rate and the product formed:

o The results confirm that the frequent renewing of solution accelerates the degradation;

o If the sulfate solution is not renewed, the degradation rate is paradoxically higher when the $\mathrm{pH}$ of the solution is not controlled;

o The presence of $\mathrm{CO}_{2}$ did not play a significant role after 160 days of exposure, except if the solution is not renewed. Indeed, in this latter case, the model predicted the precipitation of calcite in the first tenth of a millimeter. The numerical model succeeded in modeling calcite and gypsum precipitation during the first days of exposure.

However, the coupling between COMSOL and Phreeqc is very time-consuming compared to other software such as Toughreact, Hytec. ... Nevertheless, one advantage is that COMSOL is finite element software that can combine heat and chemical species flow and mechanical behavior on possible complex geometries.

\section{Acknowledgments}

The authors wish to thank Philippe Blanc for his assistance with the cement paste hydration modeling and Laurin Wissmeier for his prompt sending of the Comsol/Phreeqc coupling procedure.

\section{References}

[1] Q. Nie, C. Zhou, X. Shu, Q. He, B. Huang, Chemical, mechanical, and durability properties of concrete with local mineral admixtures under sulfate environment in Northwest China, Materials (Basel) 7 (2014) 3772-3785.

[2] Q. Nie, C. Zhou, H. Li, X. Shu, H. Gong, B. Huang, Numerical simulation of fly ash concrete under sulfate attack, Constr. Build. Mater. 84 (2015) 261-268.

[3] D.D. Higgins, Increased sulfate resistance of ggbs concrete in the presence of carbonate, Cem. Concr. Compos. 25 (2003) 913-919.

[4] A. Chabrelie, Mechanisms of degradation of concrete by external sulfate ions under laboratory and field conditions, Ecole Polytechnique Fédérale de Lausanne (2010).

[5] E. Revertegat, C. Richet, P. Gégout, Effect of $\mathrm{pH}$ on the durability of cement pastes, Cem. Concr. Res. 22 (2-3) (1992) 259-272.

[6] H. Saito, S. Nakane, S. Ikari, A. Fujiwara, Preliminary experimental study on the deterioration of cementitious materials by an acceleration method, Nucl. Eng. Des. 138 (2) (1992) 151-155.

[7] A. Neville, The confused world of sulfate attack on concrete, Cem. Concr. Res. 34 (8) (2004) 1275-1296.

[8] J. Marchand, E. Samson, Y. Maltais, J.J. Beaudoin, Theoretical analysis of the effect of weak sodium sulfate solutions on the durability of concrete, Cem. Concr. Compos. 24 (3-4) (2002) 317-329.

[9] F.P. Glasser, The thermodynamics of attack on Portland cement with special reference to sulfate, in: Concrete in Aggressive Aqueous Environments, Performance, Testing and Modeling, 2009, pp. 3-17.

[10] E. Samson, J. Marchand, Modeling the transport of ions in unsaturated cementbased materials, Comput. Struct. 85 (2007) 1740-1756.

[11] Y. Maltais, E. Samson, J. Marchand, Predicting the durability of Portland cement systems in aggressive environments-Laboratory validation, Cem. Concr. Res. 34 (9) (2004) 1579-1589.

[12] B. Lothenbach, B. Bary, P. Le Bescop, T. Schmidt, N. Leterrier, Sulfate ingress in Portland cement, Cem. Concr. Res. 40 (8) (2010) 1211-1225.
[13] J.M. Galíndez, J. Molinero, On the relevance of electrochemical diffusion for the modeling of degradation of cementitious materials, Cem. Concr. Compos. 32 (5) (2010) 351-359.

[14] R. El-Hachem, E. Rozière, F. Grondin, A. Loukili, New procedure to investigate external sulphate attack on cementitious materials, Cem. Concr. Compos. 34 (3) (2012) 357-364.

[15] L. Wissmeier, D.A. Barry, Simulation tool for variably saturated flow with comprehensive geochemical reactions in two- and three-dimensional domains, Environ. Modell. Software 26 (2) (2011) 210-218.

[16] J. van der Lee, L. De Windt, V. Lagneau, P. Goblet, Module-oriented modeling of reactive transport with HYTEC, Comput. Geosci. 29 (3) (2003) 265-275.

[17] T. Xu, E. Sonnenthal, N. Spycher, K. Pruess, TOUGHREACT-A simulation program for non-isothermal multiphase reactive geochemical transport in variably saturated geologic media: Applications to geothermal injectivity and CO2 geological sequestration, Comput. Geosci. 32 (2) (2006) 145-165.

[18] F. Adenot, M. Buil, Modelling of the corrosion of the cement paste by deionized water, Cem. Concr. Res. 22 (2-3) (1992) 489-496.

[19] H.T. Cao, L. Bucea, A. Ray, S. Yozghatlian, The effect of cement composition and $\mathrm{pH}$ of environment on sulfate resistance of Portland cements and blended cements, Cem. Concr. Compos. 19 (2) (1997) 161-171.

[20] E. Rozière, A. Loukili, R. El-Hachem, F. Grondin, Durability of concrete exposed to leaching and external sulphate attacks, Cem. Concr. Res. 39 (12) (2009) 1188-1198.

[21] P. Blanc, A. Lassin, P. Piantone, Thermoddem: A Database Devoted to Waste Minerals, Orléans, France, 2007.

[22] P. Blanc, X. Bourbon, A. Lassin, E.C. Gaucher, Chemical model for cement-based materials: Thermodynamic data assessment for phases other than C-S-H, Cem. Concr. Res. 40 (9) (2010) 1360-1374.

[23] B. Lothenbach, T. Matschei, G. Möschner, F.P. Glasser, Thermodynamic modelling of the effect of temperature on the hydration and porosity of Portland cement, Cem. Concr. Res. 38 (1) (2008) 1-18.

[24] D. Jacques, Benchmarking of the cement model and detrimental chemical reactions including temperature dependent parameters (2009).

[25] B.D.L. Parkhurst, C.A.J. Appelo, User ' S Guide To Phreeqc (Version 2)- a Computer Program for Speciation, and Inverse Geochemical Calculations, Exch. Organ. Behav. Teach. J. D (Version 2) (1999) 326.

[26] L. Liu, W. Sun, G. Ye, H. Chen, Z. Oian, Estimation of the ionic diffusivity of virtual cement paste by random walk algorithm, Constr. Build. Mater. 28 (1) (2012) 405-413.

[27] L. Yuan-Hui, S. Gregory, Diffusion of ions in sea water and in deep-sea sediments, Geochim. Cosmochim. Acta 38 (5) (1974) 703-714.

[28] COMSOL, Comsol Group, 2012.

[29] “User's guide to phreeqc (version 2)-a computer program for speciation, batch-reaction, one-dimensional transport, and inverse geochemical calculations", no. Version 2

[30] S.R. Charlton, D.L. Parkhurst, Modules based on the geochemical model PHREEQC for use in scripting and programming languages, Comput. Geosci. 37 (10) (2011) 1653-1663.

[31] Matlab, The MathWorks Inc, Natick, Massachusetts, 2012.

[32] R. Barbarulo, J. Marchand, K.A. Snyder, S. Prene, Dimensional analysis of ionic transport problems in hydrated cement systems Part 1. Theoretical considerations, Cem. Concr. Res. 30 (2000) 1955-1960.

[33] E.F. Irassar, V.L. Bonavetti, M. González, Microstructural study of sulfate attack on ordinary and limestone Portland cements at ambient temperature, Cem. Concr. Res. 33 (2003) 31-41.

[34] D. Planel, J. Sercombe, P. Le Bescop, F. Adenot, Long-term performance of cement paste during combined calcium leaching-sulfate attack: kinetics and size effect, Cem. Concr. Res. 36 (2006) 137-143.

[35] C. Sun, J. Chen, J. Zhu, M. Zhang, J. Ye, A new diffusion model of sulfate ions in concrete, Constr. Build. Mater. 39 (2013) 39-45.

[36] R. Tixier, B. Mobasher, Modeling of damage in cement-based materials subjected to external sulfate attack. II: comparison with experiments, J. Mater. Civ. Eng. 15 (2003) 314-322.

[37] B. Gérard, J. Marchand, Influence of cracking on the diffusion properties of cement-based materials Part I : Influence of continuous cracks on the steadystate regime, Cem. Concr. Res. 30 (2000) 37-43.

[38] A. Gabrisová, J. Havlica, S. Sahu, Stability of calcium sulphoaluminate hydrates in water solutions with various pH values, Cem. Concr. Res. 21 (6) (1991) 1023-1027. 